\title{
Efeitos da Chuva na Eficiência de Formulaçóes e Doses de GLYPHOSATE NO CONTROLE DE Brachiaria decumbens ${ }^{1}$
}

\author{
Rainfall Effects on Glyphosate Formulation and Rate the Efficiency to Control of \\ Brachiaria decumbens
}

WERLANG, R.C. ${ }^{2}$, SILVA, A.A. ${ }^{3}$, FERREIRA, L.R. ${ }^{3}$ e MIRANDA, G.V. ${ }^{3}$

\begin{abstract}
RESUMO - O objetivo deste trabalho foi de avaliar os efeitos de doses das formulações de glyphosate - amônio, isopropilamina e potássico - sobre o controle de plantas de Brachiaria decumbens, em condições controladas, quando submetidas à chuva com intensidade de $20 \mathrm{~mm}$ e durante 30 minutos, em intervalos de 1, 2, 4, 6, 12 e 24 horas após aplicação dos tratamentos herbicidas. A ocorrência de chuvas após a aplicação de glyphosate reduziu o controle de B. decumbens, e essa redução foi maior com a diminuição do intervalo sem chuva após a aplicação. As aplicações das formulações de glyphosate potássico e isopropilamina resultaram em maior controle da $B$. decumbens que a formulação de glyphosate amônico. Esse efeito foi também observado no acúmulo de matéria seca da rebrota da planta daninha, avaliada aos 19 dias após o corte da parte aérea das plantas. Foram necessários intervalos de pelo menos 8, 11 e 12 horas sem chuva após aplicação, respectivamente para glyphosate potássico, isopropilamina e amônio, na dose de $1.440 \mathrm{~g}$ hä, para obter controle maior que $80 \%$. $\mathrm{Na}$ dose de $2.160 \mathrm{~g}$ hả necessitou-se de intervalos de pelo menos 5, 7 e 9 horas sem chuva, respectivamente para as formulações de glyphosate potássico, isopropilamina e amônio, para proporcionar o mesmo controle de B. decumbens. Na avaliação da matéria seca acumulada na rebrota, o glyphosate potássico proporcionou controle excelente da espécie (rebrota menor do que 5\%) a partir de quatro e cinco horas sem chuva após aplicação, respectivamente nas duas maiores doses (2.160 e $\left.1.440 \mathrm{~g} \mathrm{ha}^{-1}\right)$. No caso do glyphosate isopropilamina, nas doses de 2.160 e $1.440 \mathrm{~g} \mathrm{ha}^{-1}$, o mesmo controle foi obtido a partir de 7 e 12 horas sem chuva, respectivamente. Concluiu-se que as formulações glyphosate potássico e isopropilamina são menos afetadas pela ocorrência de chuva após a aplicação e demandam menor intervalo livre de chuva do que o glyphosate amônio.
\end{abstract}

Palavras-chave: glyphosate potássico, glyphosate isopropilamina, glyphosate amônio.

\begin{abstract}
The objective of this study was to evaluate the dose effects the glyphosate formulations - ammonium, isopropylamine and potassic - on Brachiaria decumbens plant control, under controlled conditions, when submitted to $20 \mathrm{~mm}$ of rainfall intensity for 30 minutes, at intervals of 1, 2, 4, 6, 12 and 24 hours after application of the herbicide treatments. Rainfall events after glyphosate application reduced the control of $\boldsymbol{B}$. decumbens and this reduction was higher as the rainfall event was closer to the herbicide application. Potassic and isopropylamine glyphosate formulations showed a higher control of $\boldsymbol{B}$. decumbens than ammonium glyphosate formulation. This effect was also observed on the dry biomass accumulation of $\boldsymbol{B}$. decumbens regrowth, which was evaluated at 19 days after excising the plantshoot. At least 8, 11 and 12 hours after glyphosate application without rainfall were required, respectively, for potassic, isopropylamine and ammonium glyphosate at the dose of $1,440 \mathrm{~g} \mathrm{ha}^{1}$, to obtain a control over 80\%; however, for the rate of $2,160 \mathrm{~g} \mathrm{ha}^{1}$, intervals required were 5,7 , and 9 hours, at least, respectively, to obtain the same control of B. decumbens. Dry biomass accumulation oduring weed regrowth was lower than 5\%, providing an excellent control of the weed when four to five hours without rainfall occurred after herbicide application at the highest
\end{abstract}

Recebido para publicação em 14.12.2001 e na forma revisada em 2.4.2003.

2 Doutorando, Dep. de Fitotecnia da Universidade Federal de Viçosa - UFV, 36571-000, Viçosa-MG; ${ }^{3}$ Prof. do Dep. de Fitotecnia da UFV. 
two doses $\left(2,160\right.$ and 1,440 $\left.\mathrm{g} \mathrm{ha}^{1}\right)$. For isopropylamine glyphosate at the doses of 2,160 and $1,440 \mathrm{~g} \mathrm{ha}^{-1}$, the same control was obtained from 7 and 12 hours without rainfall, respectively. It was concluded that both the potassic and isopropylamine glyphosate formulations are less affected by rainfall events after herbicide application, tolerating rainfall in a shorter interval after herbicide application than ammonium glyphosate.

Key words: potassic glyphosate, isopropylamine glyphosate, ammonium glyphosate.

\section{INTRODUÇÃO}

A eficiência no controle das plantas daninhas depende da escolha do herbicida, da dose correta, das condições climáticas e de uma aplicação adequada. No campo, onde são pulverizadas áreas extensas, a ocorrência de condições climáticas inadequadas antes, no momento ou após a aplicação é fato constante, ocasionando falhas no controle, podendo até inviabilizar, do ponto de vista econômico, a cultura em questão.

O glyphosate pertence ao grupo dos inibidores da síntese de aminoácidos e contém o $\mathrm{N}$-(phosphonomethyl) glycina como ingrediente ativo (Rodrigues \& Almeida, 1998). Atualmente estão disponíveis no mercado diversas formulações de glyphosate, porém todas apresentam o mesmo mecanismo de ação, independentemente dos sais utilizados (Hartzler, 2001). Entre os sais utilizados na formulação de glyphosate têm-se: a) sal potássico (Zapp Qi); b) sal de isopropilamina (Roundup Transorb e Roundup CS); e c) sal amônio (Roundup WG e Roundup Multiação). O glyphosate, juntamente com o sulfosate e o paraquat, é o principal herbicida utilizado como dessecante no sistema de plantio direto. Ele é sistêmico, não-seletivo, altamente solúvel em água e seu mecanismo de ação baseia-se na interrupção da rota do ácido chiquímico, responsável pela produção dos aminoácidos aromáticos fenilalanina, tirosina e triptofano, essenciais para a síntese de proteínas e divisão celular nas regiões meristemáticas da planta (Hess, 1994).

Antes de apresentar ação fitotóxica, o herbicida deve ser absorvido via apoplasto e/ ou simplasto e alcançar o seu sítio de ação, geralmente localizado no interior de uma organela (Hess \& Falk, 1990). No entanto, após atingir a superfície foliar, o herbicida está sujeito a vários destinos: escorrer, ser lavado pela ocorrência de chuva, secar e formar substância amorfa, cristalizar após a evaporação do solvente ou, ainda, penetrar na cutícula e permanecer retido nela, não sendo translocado. A conseqüência imediata disso é a menor absorção e, conseqüentemente, a menor eficiência do herbicida.

As diferentes formulações de um herbicida podem alterar a absorção e a translocação do ingrediente ativo, influenciando a eficiência do controle das espécies daninhas (Silva et al., 2000). Pesquisas mostram que o glyphosate requer um período mínimo de quatro horas livre de chuva após a sua aplicação para controlar eficientemente as plantas daninhas (Bryson,1988). Segundo Pires (1998), nas formulações tradicionais, tanto para sulfosate como para glyphosate, esse período sem chuva após aplicação deve ser de, no mínimo, seis horas para Brachiaria brizantha, mesmo quando aplicados em plantas com plena atividade metabólica. No que se refere ao controle de Digitaria horizontalis, Jakelaitis et al. (2001) observaram que as formulações de glyphosate isopropilamina (Roundup Transorb), glyphosate potássico (720 g hả de eq.ac.) e, também, o sulfosate (660 $\mathrm{g}$ hd eq.ac.) apresentaram ótimo controle da espécie quando o intervalo sem chuva após as aplicações foi de 4-6 horas. Todavia, a formulação tradicional de glyphosate e a formulação de sal amônio (WG) foram as mais afetadas pela chuva em todos os intervalos avaliados, quando comparados com os demais tratamentos herbicidas.

O período crítico entre a aplicação do herbicida em pós-emergência e a ocorrência de chuva varia com o ingrediente ativo, o tipo de formulação, a dose empregada, a solubilidade do produto na água, a espécie de planta daninha e seu desenvolvimento, a quantidade e intensidade de chuva (Wicks \& Hanson, 1995; Pires, 1998; Jakelaitis et al., 2001). 
O objetivo deste trabalho foi avaliar os efeitos de doses das diferentes formulações de glyphosate - amônio (Roundup WG), isopropilamina (Roundup Transorb) e potássico (Zapp Qi) - sobre as plantas de Brachiaria decumbens, quando submetidas à chuva de $20 \mathrm{~mm}$ durante 30 minutos, nos intervalos de $1,2,4,6,12$ e 24 horas após aplicação desses produtos.

\section{MATERIAL E MÉTODOS}

O experimento foi realizado em casa de vegetação, no período de novembro de 2000 a abril de 2001, utilizando-se um Argissolo Vermelho-Amarelo câmbico, fase terraço. Sementes de Brachiaria decumbens foram semeadas em bandejas plásticas, para produção de mudas. Estas foram transplantadas, quando possuíam três folhas, em vasos com capacidade de 3,0 L, contendo solo e fertilizante. A unidade experimental foi constituída por um vaso com quatro plantas, as quais foram podadas a $5 \mathrm{~cm}$ do solo, três vezes antes da aplicação dos tratamentos, com o objetivo de obter plantas adultas e com bom desenvolvimento radical, ou seja, plantas bem estabelecidas. A irrigação dos vasos foi feita diariamente, para manter a umidade do solo próximo a $80 \%$ da capacidade de campo. Para isso foi utilizado um medidor de potencial de água no solo (Floral Sensor). Foram realizadas adubações de cobertura, semanalmente, com adubo Ouro Verde (15-15-20 NPK + pequenas quantidades de $\mathrm{Ca}, \mathrm{S}, \mathrm{Mg}, \mathrm{Zn}, \mathrm{B}, \mathrm{Fe}$ e Mn).

Aos 30 dias após a terceira poda das plantas de $B$. decumbens, quando estas apresentavam aproximadamente $55 \mathrm{~cm}$ de altura, cerca de oito perfilhos e com cerca de $15 \%$ de flores, foram aplicados os herbicidas, utilizando-se pulverizador costal pressurizado com $\mathrm{CO}_{2}$, mantendose a pressão constante em 2,5 kgf $\mathrm{cn}^{2}$, munido de barra com dois bicos XR-110.03, aplicandose o equivalente a $200 \mathrm{~L}$ ha ${ }^{1}$ de calda. As aplicações foram feitas em intervalos de $24,12,6$, 4, 2 e 1 hora entre a aplicação dos herbicidas e a simulação da chuva. Durante as aplicações, a umidade relativa do ar foi de $73 \pm 10 \%$ e a temperatura de $25 \pm 1{ }^{\circ} \mathrm{C}$. No simulador de chuvas, as plantas em vasos receberam a lâmina de $20 \mathrm{~mm}$ de água durante 30 minutos, após decorrido o intervalo de tempo preestabelecido após a aplicação dos herbicidas. A água do simulador apresentava-se com pH de 6,07 e temperatura de $21^{\circ} \mathrm{C}$.

Os tratamentos foram dispostos num esquema fatorial $(3 \times 4 \times 6)+1$, ou seja, três formulações de glyphosate (sal potássico Zapp Qi; sal isopropilamina - Roundup Transorb; e sal amônio - Roundup WG), quatro doses de glyphosate $(360,720,1.440 \mathrm{e}$ $2.160 \mathrm{~g}$ hà eq.ac.), seis intervalos sem chuva após as aplicações dos herbicidas $(1,2,4,6$, 12 e 24 horas) e a testemunha sem herbicida, em delineamento inteiramente casualizado, com três repetições.

Os herbicidas utilizados no experimento foram: Zapp Qi - formulação comercial (SA) com $50 \%$ de glyphosate sal potássico; Roundup Transorb - formulação comercial (SA) com 48\% de glyphosate sal isopropilamina; e Roundup WG - formulação comercial (WG) com $72 \%$ de glyphosate sal amônio.

A eficiência de controle de $B$. decumbens foi avaliada aos 7, 14 e 21 dias após a aplicação (DAA), com base nos sintomas de fitointoxicação, utilizando-se a escala de Frans (1972), em que $0 \%$ correspondeu à ausência de sintomas visíveis e $100 \%$ à morte das plantas. Aos 39 DAA, as plantas foram cortadas a $5 \mathrm{~cm}$ do solo e, decorridos 19 dias, determinou-se a matéria seca da rebrota por vaso. O material vegetal foi secado em estufa de circulação forçada de ar a $70{ }^{\circ} \mathrm{C}$ até adquirir peso constante. Os resultados foram expressos por percentagem em relação à testemunha sem herbicida.

Durante o período do experimento as médias das temperaturas máxima e mínima e da umidade relativa do ar no interior da casa de vegetação foi, respectivamente, de $36 \pm 2$, $21 \pm 2$ e $60 \pm 13$.

Os dados foram interpretados por meio de análise de variância e regressão. Para o fator qualitativo (formulações) as médias foram comparadas utilizando o teste de Tukey, adotandose o nível de $5 \%$ de probabilidade. Em se tratando dos fatores quantitativos, utilizou-se a metodologia de superfície de resposta, e os modelos foram escolhidos com base na significância dos coeficientes de regressão, utilizando o teste de " $t$ " em nível de $5 \%$ de probabilidade, no coeficiente de determinação e no fenômeno em estudo. Na interpretação dos dados das avaliações de controle a testemunha 
não foi considerada, uma vez que os valores da percentagem de controle são obtidos tendo ela como referência.

As funções foram analisadas e trabalhadas para visualização gráfica pelo software Statistica (1999). Para melhor visualização dos resultados obtidos, o controle de $B$. decumbens foi dividido em cinco faixas: 90 a $100 \%=$ controle excelente ou total; 80 a $90 \%=$ controle bom; 70 a $80 \%=$ controle moderado; 50 a $70 \%=$ controle deficiente ou inexpressivo; e $<$ que $50 \%=$ controle inadequado.

\section{RESULTADOS E DISCUSSÃO}

Após a realização das análises de variância, algumas das interações foram estudadas por superfície de resposta, mesmo não sendo significativas, porém, por demonstrarem importância quanto ao fenômeno em estudo, foi determinada a melhor função que explicasse os resultados analisados. Houve efeito de formulações, doses e intervalos de chuva em todas as características avaliadas. Os fatores mais importantes quanto à resposta na planta estudada foram, na ordem decrescente de importância, as doses e os intervalos sem chuva após a aplicação. As formulações possuíram o menor valor de quadrado médio, o que já era esperado, em razão da alta eficácia delas. Não houve interação significativa entre os três fatores estudados, entretanto o desdobramento das doses e dos intervalos sem chuva foi realizado para cada formulação, devido à importância dessas informações.

O intervalo de 24 horas sem chuva após a aplicação não foi incluído na metodologia da superfície de resposta em razão da falta de ajuste entre a função e os resultados biológicos, quando em sua consideração na análise, uma vez que os resultados obtidos no intervalo de 12 horas sem chuva após a aplicação foram semelhantes aos do intervalo de 24 horas. Para o estudo estatístico da superfície obtida foi realizada análise de variância, em que o intervalo de 24 horas sem chuva após a aplicação não foi considerado.

Os efeitos das diferentes formulações de glyphosate são apresentados na Tabela 1 . O glyphosate potássico (Zapp Qi) proporcionou controle de $B$. decumbens superior ao das demais formulações aos 14 DAA, sendo semelhante ao do glyphosate isopropilamina (Roundup Transorb) aos 21 DAA. A média de controle foi de 53,50 e 47\%, respectivamente para o glyphosate potássico, isopropilamina e amônio; portanto, a diferença na eficácia das formulações foi pequena. Esse efeito também foi observado no acúmulo de matéria seca da rebrota, em que a diferença da matéria seca da parte aérea da rebrota entre as formulações glyphosate isopropilamina e potássico foi de apenas 0,19 g. Já o glyphosate amônio (Roundup WG) proporcionou controle inferior da espécie estudada, apresentando $49 \%$ de rebrota, quando comparado com $37 \%$ de rebrota do glyphosate potássico.

O efeito da interação das formulações de glyphosate com os intervalos sem chuva após a aplicação, no controle de $B$. decumbens aos 7 DAA, encontra-se na Figura 1. As formulações se diferenciaram no controle da espécie apenas no intervalo de 12 horas livre de chuva após a aplicação, quando o glyphosate potássico foi superior às demais formulações.

Os resultados da eficiência de controle de B. decumbens pelas diferentes formulações de glyphosate em função das doses e do intervalo de tempo sem chuva após aplicação podem ser observados na Figura 2. A faixa de controle ( $>80 \%$ ), ou seja, a combinação de doses e intervalos sem chuva após a aplicação, foi maior para as formulações glyphosate potássico e isopropilamina do que para o glyphosate amônio no controle da espécie estudada, semelhantemente ao observado por Jakelaitis et al. (2001). Esses resultados foram diferentes dos verificados no controle visual de Bidens pilosa (dados não publicados), em que o glyphosate amônio proporcionou maior toxidez visual do que as formulações glyphosate potássico e isopropilamina.

A ocorrência de chuvas após a aplicação de glyphosate proporcionou redução no controle de $B$. decumbens (Figura 2a, b, c). Essa redução foi maior quando se diminuiu o intervalo sem chuva após a aplicação. A redução da eficácia de controle proporcionado pelo glyphosate devido à ocorrência de chuvas após a aplicação também foi observada por Bryson (1988), Pires (1998) e Jakelaitis et al. (2001); semelhantemente ao observado neste trabalho, a redução foi maior quando a chuva ocorreu em menores intervalos após a aplicação. 
Tabela 1 - Valores médios ${ }^{1 /}$ de controle e matéria seca da rebrota de Brachiaria decumbens em função das diferentes formulações de glyphosate

\begin{tabular}{|l|c|c|c|c|}
\hline \multirow{2}{*}{ Formulação } & \multicolumn{2}{|c|}{ Controle Visual (\%) } & \multicolumn{3}{|c|}{ Matéria Seca da Rebrota $^{\underline{2} /}$} \\
\cline { 2 - 5 } & 14 DAA & 21 DAA & g/vaso & Percentagem $^{3 /}$ \\
\hline Glyphosate potássico & $42 \mathrm{a}^{*}$ & $53 \mathrm{a}$ & $1,35 \mathrm{c}$ & $37 \mathrm{c}$ \\
Glyphosate isopropilamina & $39 \mathrm{~b}$ & $50 \mathrm{a}$ & $1,54 \mathrm{bc}$ & $42 \mathrm{bc}$ \\
Glyphosate amônio & $35 \mathrm{c}$ & $47 \mathrm{~b}$ & $1,76 \mathrm{~b}$ & $49 \mathrm{~b}$ \\
Testemunha sem herbicida & 0 & 0 & $3,64 \mathrm{a}$ & $100 \mathrm{a}$ \\
\hline CV $(\%)$ & 22,2 & 18,76 & 51,0 & 51,0 \\
\hline
\end{tabular}

${ }^{1 /} \mathrm{n}=72$, intervalos sem chuva após a aplicação e doses de glyphosate. ${ }^{2 /}$ Obtida 19 dias após o corte das plantas (g/vaso). ${ }^{3 /}$ Em relação à testemunha $(100 \%)$ * Médias seguidas pelas mesmas letras na coluna não diferem entre si, pelo teste de Tukey, a $5 \%$ de probabilidade.

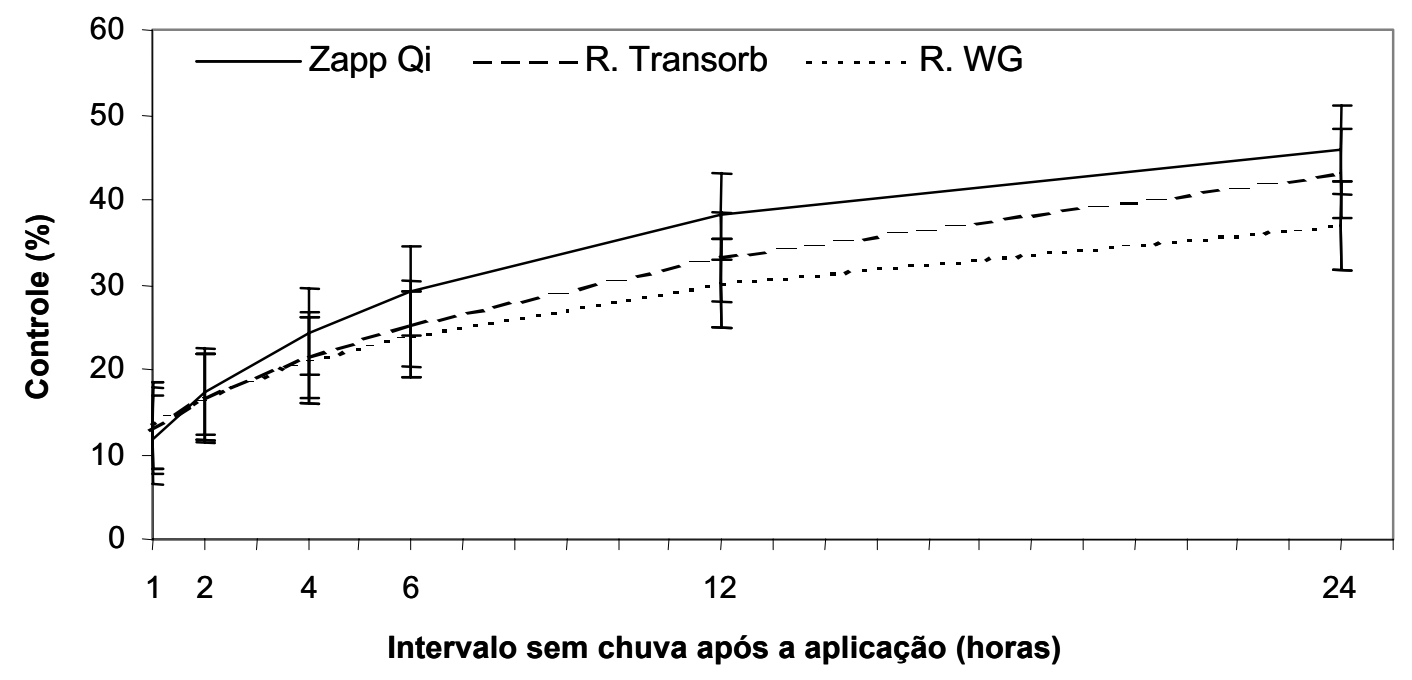

Zapp Qi : $\hat{y}=-3,65+16,73 *(\text { chuva })^{1 / 2}-1,35 *$ (chuva) $R^{2}=0,77$

Roundup Transorb: $\hat{y}=3,37+9,85^{*}(\text { chuva })^{1 / 2}-0,36^{*}($ chuva $) R^{2}=0,80$

Roundup WG: $\hat{y}=4,83+9,19 *(\text { chuva })^{1 / 2}-0,54 *($ chuva $) R^{2}=0,83$

* Significativo a $5 \%$ pelo teste de "t". Barras sobrepostas não diferem no intervalo sem chuva pelo teste de Tukey a $5 \%$ de probabilidade.

Figura 1 - Valores médios $(\mathrm{n}=12)$ de controle de Brachiaria decumbens aos sete dias após a aplicação, em função das diferentes formulações de glyphosate e dos intervalos sem chuva após aplicação.

Todas as formulações de glyphosate foram afetadas pela ocorrência de chuva após aplicação, como pode ser observado na Figura 2. Esse efeito foi mais evidente nas menores doses deste herbicida, independentemente da formulação estudada, uma vez que estas foram mais afetadas pela ocorrência da chuva. O glyphosate potássico na dose de $1.440 \mathrm{~g}$ hả proporcionou desde controle inferior a $50 \%$ com o intervalo sem chuva de uma hora até controle maior do que $80 \%$ com oito horas sem chuva; já na dose de $2.160 \mathrm{~g}$ hả foi necessário pelo menos cinco horas para proporcionar o mesmo controle (Figura 2a). Diferentes resultados foram obtidos por Jakelaitis et al. (2001), em que seis horas sem chuva após aplicação não diferiu da testemunha sem chuva, no controle de $D$. horizontalis com glyphosate potássico na dose de $720 \mathrm{~g}$ had. Possivelmente isso se deve à maior suscetibilidade de $D$. horizontalis ao glyphosate do que $B$. decumbens além das diferenças do estágio de desenvolvimento das espécies no momento da aplicação. 
(a)

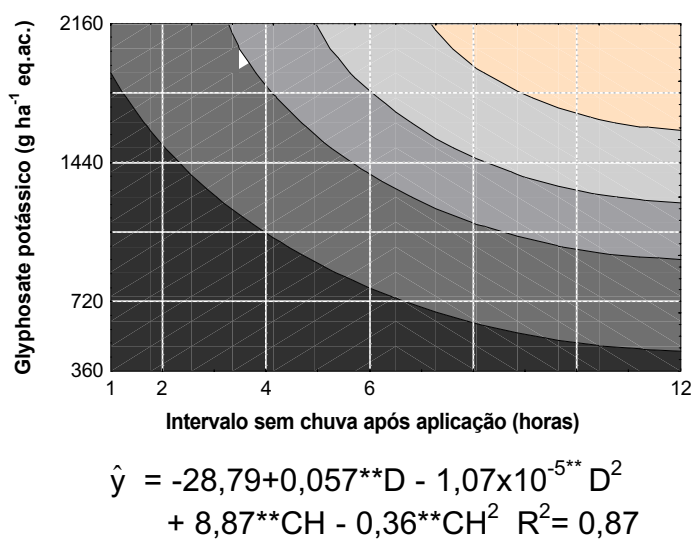

(c)

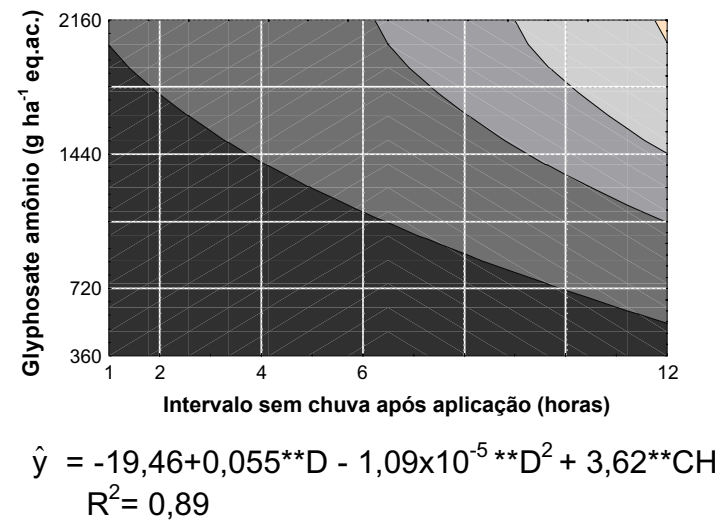

(b)

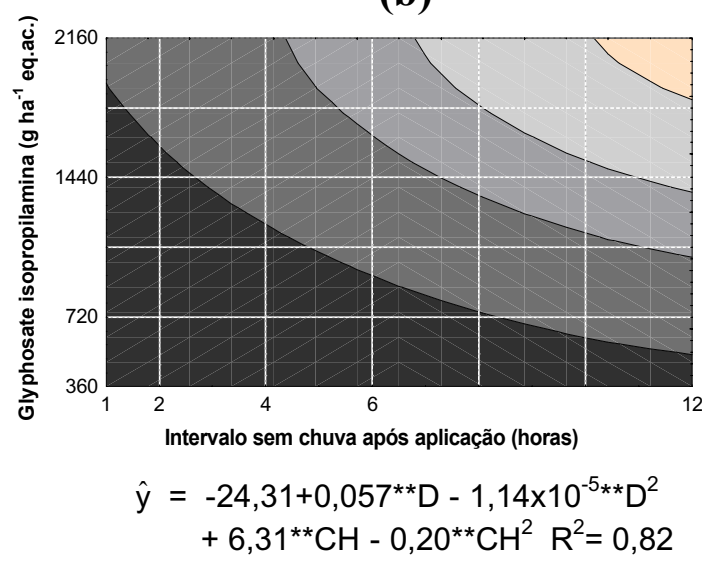

(d) Intervalo de 24 horas sem chuva após a aplicação**

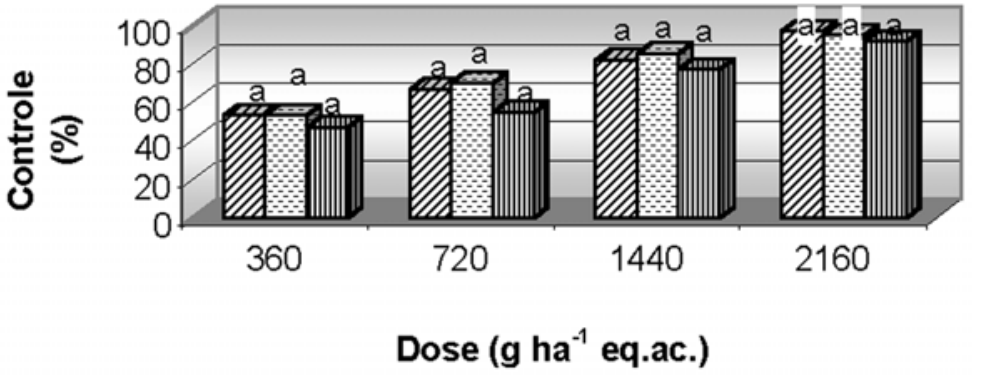

\section{चPotássico Đilsopropilamina m Amônio}

** Significativo a $1 \%$ pelo teste de "t". *Médias seguidas pela mesma letra não diferem entre si pelo teste de Tukey a $5 \%$ de probabilidade. Abreviações - D: dose. $\mathrm{CH}$ : chuva.

Figura 2 - Percentagem de controle $(\hat{y})$ de Brachiaria decumbens aos 21 dias após a aplicação (DAA), em função das doses de (a) glyphosate potássico, (b) glyphosate isopropilamina e (c) glyphosate amônio e dos intervalos sem chuva após aplicação (20 mm em 30 minutos). Em (d) a percentagem de controle da espécie no intervalo de 24 horas sem chuva após a aplicação foi em função das formulações e doses de glyphosate. 
Foi necessário um intervalo de pelo menos 11 e 12 horas sem chuva após aplicação, respectivamente para glyphosate isopropilamina e amônio, ambos na dose de $1.440 \mathrm{~g}$ hả, para proporcionar controle de $B$. decumbens maior do que $80 \%$. Já na dose de $2.160 \mathrm{~g}$ há foi necessário intervalo de pelo menos sete e nove horas sem chuva, respectivamente para as formulações de glyphosate isopropilamina e amônio, para proporcionar controle maior do que $80 \%$ de $B$. decumbens.

Os resultados da rebrota de $B$. decumbens em relação à testemunha sem herbicida pelas diferentes formulações de glyphosate, em função das doses e do intervalo de tempo sem chuva após aplicação, podem ser observados na Figura 3.

A eficiência de controle de $B$. decumbens foi diferenciada para cada dose de glyphosate, sendo as menores rebrotas observadas nas maiores doses (melhor controle). Esse resultado ficou mais evidente quando se avaliou o acúmulo da matéria seca da rebrota das plantas (Figura 3). O glyphosate isopropilamina no intervalo de uma e duas horas sem chuva após a aplicação proporcionou, na menor dose (360 g ha), rebrota maior do que $89 \%$, porém na maior dose (2.160 $\left.\mathrm{g} \mathrm{ha}^{1}\right)$ a rebrota foi de 5 a 29\% (Figura 3b).

Nos intervalos de uma a quatro horas sem chuva após a aplicação, o controle da espécie foi muito afetado pelas doses de glyphosate, independentemente da formulação. O efeito das doses no controle de $B$. decumbens foi mais evidente nos intervalos sem chuva inferiores a seis horas, sendo esse efeito mais visível no caso do glyphosate potássico (Figura 3a).

A maior dose do herbicida influencia a maior quantidade absorvida, translocada e que alcança o local de ação; portanto, doses maiores exigem menor intervalo sem chuva, para controle eficiente. Esse resultado foi semelhante ao observado por Wicks et al. (1993), em que a redução do controle de Echinochloa colonum na dose de $225 \mathrm{~g} \mathrm{ha}^{-1}$ de glyphosate, com a ocorrência de chuva de $3 \mathrm{~mm}$ após aplicação, exigiu intervalo de 45 horas sem chuva para se obter controle de $73 \%$. No entanto, na dose de $900 \mathrm{~g}$ had de glyphosate, o controle de $93 \%$ foi alcançado com seis horas sem chuva após aplicação.
A eficiência do controle das plantas daninhas pelos herbicidas é dependente de sua ação na planta. É necessário, entretanto, que a molécula seja absorvida e translocada até o local de ação, em quantidade adequada, onde desempenhará sua função. Até alcançar o local de ação, a molécula deve passar por várias barreiras, e o glyphosate sozinho não passa facilmente por todas elas, sendo a formulação de extrema importância na eficiência do herbicida, uma vez que se constitui de substância que melhora as condições de permanência, absorção, solubilidade e translocação na planta (Laerke \& Streibig, 1995). As formulações dos herbicidas possuem diferentes surfatantes e estes possuem comportamento diferenciado quanto à sua ação (Laerke \& Streibig, 1995), justificando, assim, a variação na resposta no controle de $B$. decumbens pelas diferentes formulações de glyphosate.

A taxa de absorção de diferentes formulações de glyphosate é superior à medida que a gota aplicada está secando (Stevens et al., 1991), devido ao incremento da concentração do herbicida enquanto a gota perde água. Segundo Liu et al. (1996), a formação de maior gradiente de concentração entre a gota e a folha e a maior permanência do herbicida sobre a folha são os principais fatores que aumentam a absorção. A formulação do glyphosate influencia, ainda, o tempo de permanência da gota, em condição adequada de absorção sobre a folha (Nalewata et al., 1996), sem que ocorra a formação de cristal ou forma amorfa. Assim, a velocidade de absorção e a quantidade do herbicida absorvido são afetadas, o que é refletido na maior eficiência de controle das plantas daninhas e, conseqüentemente, menor influência da ocorrência de chuva após aplicação. Isso também foi observado nas formulações glyphosate potássico e isopropilamina, que foram menos prejudicadas pela ocorrência de chuva após a aplicação do que a de glyphosate amônio (Figuras 2 e 3 ).

Comparando os efeitos das formulações em cada intervalo sem chuva após aplicação e em cada dose, verificou-se que glyphosate amônio foi menos eficiente, exigindo intervalos sem chuva e doses maiores, sugerindo ser mais facilmente lavado que glyphosate potássico e isopropilamina, semelhante ao observado por Jakelaitis et al. (2001) em D. horizontalis.

Planta Daninha, Viçosa-MG, v.21, n.1, p.121-130, 2003 
(a)

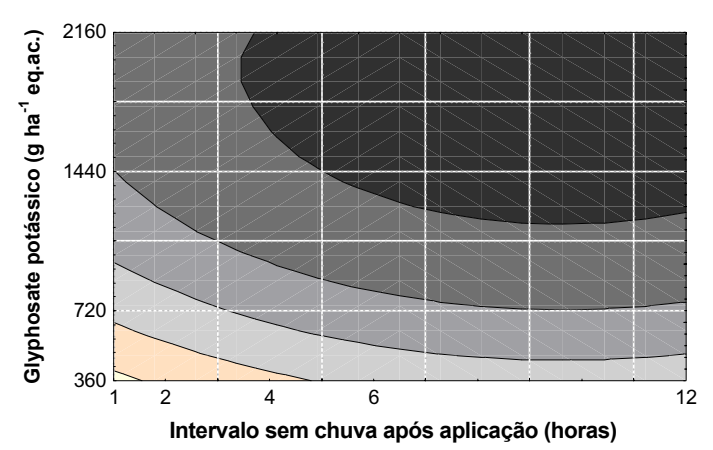

$\hat{y}=138,66-0,11^{* *} D+2,79 \times 10^{-5 * *} D^{2}-9,12^{* *} C H$

$+0,47^{* *} \mathrm{CH}^{2} \mathrm{R}^{2}=0,79$ (b)

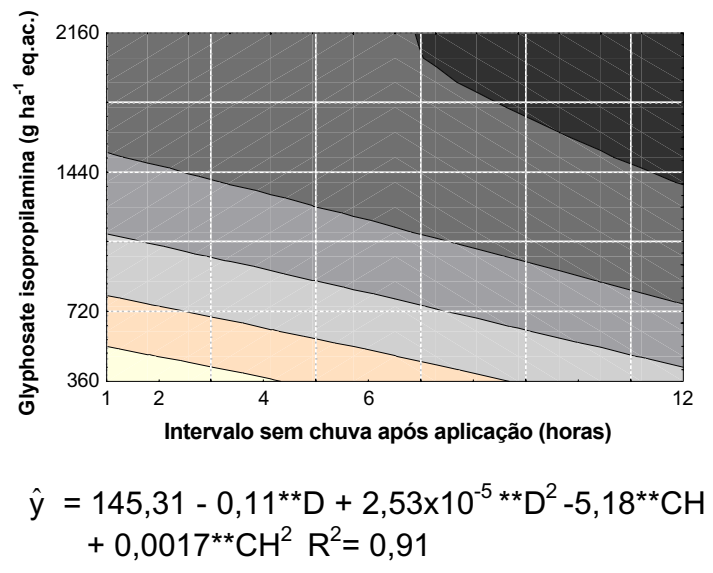

(c)

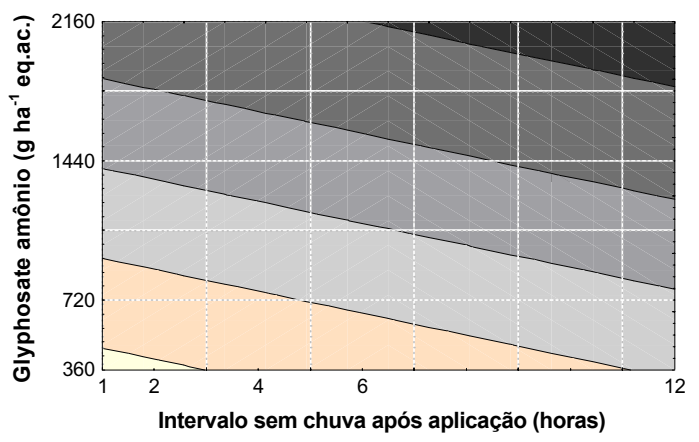

Rebrota (\%)

$<5$

5 a 29

30 a 49

50 a 69

70 a 89

$>89$

(d) Intervalo de 24 horas sem chuva após a aplicação.*

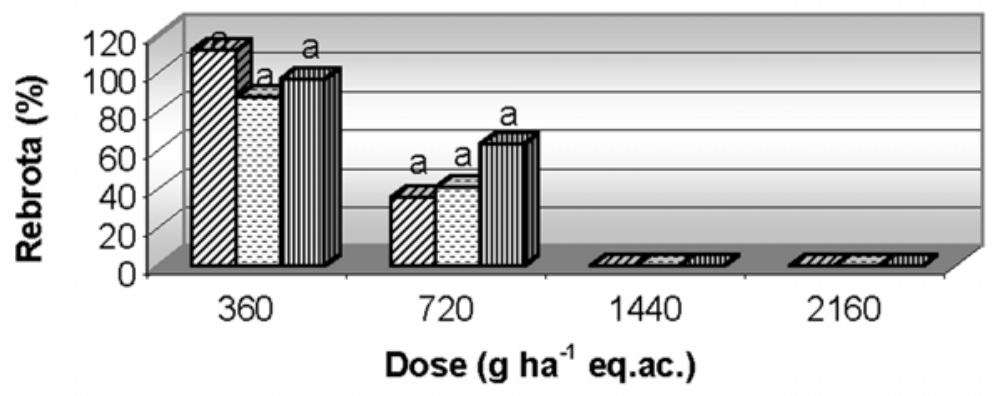

\section{■Potássico Đlsopropilamina mAmônio}

** Significativo a $1 \%$ pelo teste de “t”. *Médias seguidas pela mesma letra não diferem entre si pelo teste de Tukey a 5\% de probabilidade. Abreviações - D: dose. $\mathrm{CH}$ : chuva.

Figura 3 - Percentagem de rebrota $(\hat{y})$ de Brachiaria decumbens obtida pela relação entre a matéria seca dos tratamentos e a da testemunha sem herbicida, aos 19 dias após o corte, em função das doses de (a) glyphosate potássico, (b) glyphosate isopropilamina e (c) glyphosate amônio e dos intervalos sem chuva após aplicação ( $20 \mathrm{~mm}$ em 30 minutos). Em (d) a percentagem de rebrota da espécie no intervalo de 24 horas sem chuva após a aplicação foi em função das formulações e doses de glyphosate. 
As diferenças observadas no efeito das doses e da ocorrência de chuva após aplicação e suas interações, no controle de $B$. decumbens, mesmo trabalhando com a mesma quantidade de equivalente ácido do herbicida nas formulações de glyphosate, possivelmente se devem às diferentes taxas de absorção dos sais presentes nestas. De acordo com Nalewaja et al. (1996), a absorção relativa à quantidade aplicada foi de 59\% para o sal isopropilamina, $44 \%$ para o sal amônio, $21 \%$ para o sal sódico e $1 \%$ para o sal cálcico. No entanto, a taxa de absorção dos diferentes sais também é influenciada pela interação destes com os surfatantes presentes nas formulações. Nalewaja et al. (1996), estudando o efeito de vários sais de glyphosate na redução da matéria seca de trigo, observaram que todas as formulações de glyphosate foram menos eficientes quando aplicadas com X-77 do que com MON 0818 ou Tween 20 a $1 \%$ na solução e que o sal isopropilamina foi o mais ativo, independentemente do surfatante.

Quanto ao estudo da rebrota de Brachiaria decumbens (Figura 3), o glyphosate potássico proporcionou controle excelente desta espécie (rebrota menor do que 5\%) a partir de quatro e cinco horas sem chuva após aplicação, respectivamente, nas duas maiores doses $(2.160 \mathrm{e}$ $1.440 \mathrm{~g}$ ha). Para o glyphosate isopropilamina nas doses de 2.160 e $1.440 \mathrm{~g} \mathrm{ha}^{-1} \mathrm{o}$ mesmo controle foi obtido, respectivamente, a partir de 7 e 12 horas sem chuva. Já o efeito do glyphosate amônio foi mais afetado pela chuva que o das demais formulações, apresentando este nível de controle apenas na maior dose, exigindo sete horas livre de chuva após a aplicação. Possivelmente, ocorreu maior translocação para as regiões meristemáticas da planta no caso do glyphosate potássico e isopropilamina, proporcionando controle excelente aos 21 DAA, tendo como conseqüência menor percentual de rebrota em relação à testemunha sem herbicida em todos os intervalos e doses avaliados.

O glyphosate é facilmente influenciado pela ocorrência de chuva após aplicação, devido à sua absorção relativamente lenta. Bryson (1988), estudando o efeito de intervalos sem chuva no controle de plantas novas de Sorghum halepense, observou que os herbicidas ácidofosfonados (glyphosate e SC-0224) precisaram de períodos bem superiores aos exigidos pelos herbicidas seletivos estudados. Segundo Bariuan et al. (1999), a absorção de $\mathrm{C}^{14}$ glyphosate sal isopropilamina aumentou de $2,84 \%$ uma hora após a aplicação para 4,18 ; 6,$42 ; 8,35$; e $21,39 \%$, respectivamente 6,24 , 72 e 168 horas após aplicação de Roundup Ultra (560 $\mathrm{g} \mathrm{ha}^{-1}$ do produto comercial) em Cyperus rotundus.

As diferentes respostas das formulações estudadas na menor produção da matéria seca acumulada, em função da ocorrência de chuva após aplicação e sua interação com as doses, possivelmente, se devem às diferentes taxas de absorção de glyphosate para cada formulação, conforme mencionado por Feng et al. (2000). Os autores demonstraram que a taxa de absorção varia para as diferentes formulações e, também, é afetada pelo intervalo sem chuva; determinada formulação pode possuir melhor absorção em períodos iniciais após aplicação, caindo posteriormente.

O herbicida ainda não absorvido é vulnerável à ação da chuva, que pode lavá-lo da superfície foliar, ocasionando redução do controle das plantas daninhas e conseqüente perda econômica, além do risco potencial de contaminação do ambiente. O glyphosate apresenta, em geral, baixo potencial de contaminação do solo, uma vez que é fortemente adsorvido aos colóides do solo e rapidamente degradado pelos microrganismos (Rodrigues \& Almeida, 1998), embora o resíduo do glyphosate, em solos arenosos e com baixa atividade microbiana, possa causar injúrias em algumas culturas (Cornish, 1992; Piccolo et al., 1994).

As diferentes formulações de glyphosate afetam a quantidade do herbicida lavado da superfície foliar, como observado por Feng et al. (2000). As diferenças foram marcantes com a chuva ocorrendo 24 horas após a aplicação, em que a percentagem do Roundup Ultra (sal isopropilamina) recuperado na água da chuva foi de $71,8 \%$, comparada a 83,8 e $86,7 \%$, respectivamente, para Sulfosate 5 (sal trimetilsulfônico de sulfosate) e Roundup Original (sal isopropilamina). Conseqüentemente, o Roundup Ultra foi mais eficiente que os demais, sendo mais absorvido por Abutilon theophrasti, em particular nos intervalos de 4 e 24 horas após aplicação.

Portanto, a velocidade de absorção do glyphosate é componente importante do seu

Planta Daninha, Viçosa-MG, v.21, n.1, p.121-130, 2003 
desempenho quanto à sua ação herbicida, principalmente quando ocorrem chuvas após a aplicação.

\section{LITERATURA CITADA}

BARIUAN, J. V.; REDDY, K. N.; WILLS, G. D. Glyphosate injury, rainfastness, absorption, and translocation in purple nutsedge (Cyperus rotundus). Weed Technol., v. 13, p. 112-119, 1999.

BROMILOW, R. H.; CHAMBERLAIN, K.; EVANS, A. A. Physiocochemical aspects of phloem translocation of herbicide. Weed Sci., v. 38, p. 305-314, 1990.

BRYSON, C. T. Effects of rainfall on foliar herbicides applied to seedling johnsongrass. Weed Technol., v. 2, p. $153-158,1988$

CORNISH, P. S. Glyphosate residues in a sandy soil affect tomato transplants. Aust. J. Exp. Agric., v. 32, n. 3, p. 395-399, 1992.

FENG, P. C. C.; SANDBRINK, J. J.; SAMMONS, R. D. Retention, uptake, and translocation of ${ }^{14} \mathrm{C}$-glyphosate from track-spray applications and correlation to rainfastness in velvetleaf (Abutilon theophrasti). Weed Technol., v. 14, p. $127-132,2000$.

FRANS, R. E. Measuring plant responses. In: WILKINSON, R. E. (Ed.). Research methods in weed science. [s.1.]: Southern Weed Science Society, 1972. p. 2841.

HARTZLER, B. Which glyphosate product is best? Disponível em 28/01/2001 - http:www.weeds.iastate.edu/ mgmt/qtr01-1/glyphosateformulations.htm.

HESS, F. D. Mechanism of action of inhibitors of amino acid biosynthesis. In: Herbicide action: an intensive course on the activity, selectivity, behavior, and fate of herbicides in plants and soil. West Lafayette: Purdue University, 1994. p. 344-365.

HESS, F. D.; FALK, R. H. Herbicide deposition on the leaf surface. Weed Sci., v. 38, p. 280-288, 1990.
JAKELAITIS, A. et al. Controle de Digitaria horizontalis pelos herbicidas glyphosate, sulfosate e glifosate potássico submetidos a diferentes intervalos de chuva após a aplicação. Planta Daninha, v. 19, n. 2, p. 279-285, 2001.

LAERKE, P. E.; STREIBIG, J. C. Foliar absorption of some glyphosate formulations and their efficacy on plants. Pesticide Sci., v. 44, p. 107-116, 1995.

LIU, S. H. et al. Absorption and translocation of glyphosate in Aspen (Populus tremuloides Michx.) as influenced by droplet size, droplet number, and herbicide concentration. Weed Sci., v. 44, p. 482-488, 1996.

NALEWAJA, J. D.; DEVILLIERS, B.; MATYSIAK, R. Surfactant and salt affect glyphosate retention and absorption. Weed Res., v. 36, p. 241-247, 1996.

PICCOLO, A. et al. Adsorption and desorption of glyphosate in some european soils. J. Environ. Sci. Health, Part B, v. 6, p. 1105-1115, 1994.

PIRES, N. M. Efeitos do glyphosate e do sulfosate após simulação de chuva em plantas de Brachiaria brizantha submetidas ao estresse hídrico. 1998. $100 \mathrm{f}$. Tese (Doutorado em Fitotecnia) - Universidade Federal de Viçosa,Viçosa-MG, 1998.

RODRIGUES, B. N.; ALMEIDA, F. S. Guia de herbicidas. Londrina: Edição dos Autores, 1998. 648 p.

SILVA, A. A. et al. ABEAS. Módulo 3. Controle de plantas daninhas. Viçosa-MG: ABEAS, 2000. 260 p.

STATISTICA program/documentation. StatSoft, In. (1999). Statistica for Windows (Computer program manual).

STEVENS, P. J. G. et al. Contributions of stomatal infiltration and cuticular penetration to enhancements of foliar uptake by surfactants. Pesticide Sci., v. 33, p. 371$382,1991$.

WICKS, G. A.; FELTON, W. L.; WELSBY, S. M. Effect of rainfall on glyphosate performance on stressed grass weeds following wheat harverst. Plant Prot. Quart., v. 8, n. 1, p. 2-6, 1993

WICKS, G. A.; HANSON, G. E. Effect of rainfall on glyphosate plus 2,4-D performance on Echinochloa crusgalli. Weed Sci., v. 43, p. 666-670, 1995. 